\title{
ACÚMULO DE MASSA SECA E ANÁLISE BROMATOLÓGICA DE DIFERENTES GENÓTIPOS DE PALMA MIÚDA EM DIFERENTES TIPOS DE ADUBAÇÃO.
}

\author{
$\underline{\text { Jade Cavalcante de Oliveira }}^{1}$; Marilza Neves do Nascimento ${ }^{2}$; Cássio Gyovanne de \\ Aquino Amorim ${ }^{3}$ \\ 1. Graduanda em Agronomia Departamento de Ciências Biológicas, Universidade Estadual de Feira de Santana, e- \\ mail: jady_fcg@hotmail.com \\ 2. Professora Adjunta, Departamento de Ciências Biológicas, Universidade Estadual de Feira de Santana, e-mail: \\ marilzaagro@hotmail.com \\ 3. Graduando em Agronomia Departamento de Ciências Biológicas, Universidade Estadual de Feira de Santana, e- \\ mail: cassiogyovanneagro@ hotmail.com
}

PALAVRAS-CHAVE: Análises bromatológicas, palma forrageira, adubação.

\section{INTRODUÇÃO}

O semiárido nordestino abrange uma área com cerca de $841.260 \mathrm{~km}^{2}$ (quase 54 $\%$ do Nordeste do Brasil), caracterizada por um alto índice de evaporação anual, superior a $2000 \mathrm{~mm}$ e média anual de chuvas inferior a $750 \mathrm{~mm}$, concentrados em uma única estação, que dura entre 3 e 5 meses. Em alguns anos a estiagem é prolongada, provocando a tragédia das secas. Esse fator desestabiliza as frágeis economias instaladas, gerando o êxodo das populações mais desprotegidas, agravando os problemas da região (BANCO DO NORDESTE, 2005).

A escassez de alimentos volumosos para ruminantes, principalmente durante o período de baixa densidade pluviométrica, é um problema que se repete anualmente no nordeste brasileiro, refletindo na baixa produtividade dos rebanhos manejados em regime de pastejo. A limitação das fontes proteicas e energéticas disponíveis exige suplementação alimentar, elevando consideravelmente os custos de produção. Por outro lado, o fornecimento de forrageiras existentes na região pode suprir, em parte, a deficiência das pastagens nos períodos de estiagem a custos relativamente baixos (Vieira et al., 2005).

$\mathrm{Na}$ época das chuvas a disponibilidade de forragens é quantitativa e qualitativamente satisfatória, no entanto, nas épocas críticas do ano, além da escassez de forragens, o valor nutritivo das mesmas se apresenta baixo, acarretando queda na produtividade, comprometendo assim a produção de carne e leite. Nesse período, em que as deficiências de energia e proteína são mais evidentes, a palma forrageira (Nopalea coccinellifera Salm-Dyck) apresenta-se com maior valor nutritivo devido ao aumento do teor de matéria seca, mas ainda com grande quantidade de água nos seus cladódios, constituindo-se então como uma importante reserva estratégica de alimento, sendo amplamente fornecida aos animais (Lima et al., 2004).

Em estudos comparativos entre as cultivares Gigante, Redonda e Miúda, foram encontradas variações na composição química das mesmas, sendo que, a cultivar Miúda se destacou por apresentar maior teor de matéria seca e digestibilidade. Tendo em vista os dados relatados, este projeto tem como objetivo analisar a composição bromatológica da palma forrageira miúda, por meio da determinação de teores de proteína bruta e carboidratos, em diferentes tipos de adubação, para utilização na alimentação animal.

\section{MATERIAL E MÉTODOS}


Os experimentos foram conduzidos na Unidade Experimental Horto Florestal que se localiza na cidade de Feira de Santana. Para implantação da área experimental foi utilizado um clone selecionado por Oliveira (2010), V26 e o clone IPA sertânea, ambos pertencentes à palma miúda (Nopalea cochenillifera Salm-Dyck). Antes do plantio foi realizada análise de solo e as correções necessárias para o preparo da área.

O delineamento experimental foi em blocos ao acaso em esquema fatorial $4 \times 2$, com três repetições. Cada bloco foi formado por três tratamentos, sendo o tratamento 1 (T1) sem adubação, o tratamento 2 (T2) esterco bovino (30 t ha-1), o tratamento 3 (T3) adubo químico mistura NPK (dose de acordo com a análise de solo). Cada genótipo foi disposto em três fileiras contendo dez plantas cada, totalizando 30 repetições por tratamento, dentro de cada bloco. Foram coletadas amostras aos 8 meses após a implantação do experimento para a determinação da massa seca das plantas e para as análises bromatológicas. As plantas foram coletadas e pesadas com auxílio de balança digital. Posteriormente, os cladódios foram submetidos à secagem em estufa de ventilação forçada a $65^{\circ} \mathrm{C}$, por um período de quinze dias e posteriormente trituradas em moinho para determinação da massa seca e cinzas. Para determinação de proteína bruta foi utilizado o método de Kjeldahl, que se caracteriza como determinação indireta, pois não determina a quantidade de proteína e sim o nitrogênio orgânico total. Esse processo inclui quatro passos que são: a. Digestão, neutralização e destilação e titulação.

Para a realização das análises de cinzas, pesou-se $5 \mathrm{~g}$ da amostra em uma cápsula de porcelana que foram posteriormente aquecidas em mufla a $550^{\circ}$ por cerca de três horas, após o tempo estimado as amostras foram retiradas da mufla e resfriada em dessecador até temperatura ambiente. $\mathrm{O}$ cálculo para o teor de cinzas se deu pela equação $(100 \mathrm{X} \mathrm{N}) / \mathrm{P}=$ cinzas por cento $\mathrm{m} / \mathrm{m}$, onde $\mathrm{N}$ é o número de $\mathrm{g}$ de cinza, $\mathrm{P}$ é o número de $\mathrm{g}$ da amostra.

\section{RESULTADOS E/OU DISCUSSÃO}

De acordo com os dados obtidos na análise de variância (Tabela 1), para fontes de variação avaliadas, apenas houve diferenças significativas para os tratamentos. Indicando que há um efeito dos tipos de adubações nas características dos clones avaliados. Observou-se que para as fontes de variação genótipo, bloco e interação tratamentos x genótipos não houve diferenças significativas.

Tabela 1. Análise de variância e coeficientes de variação experimental para os caracteres cinzas ou matéria mineral $(\mathrm{MM})$, proteína bruta $(\mathrm{PB})$ e produtividade de massa seca (PRODMS) (Kg/Ha) avaliadas em dois clones de palma miúda (Nopalea cochenillifera Salm- Dyck) cultivados sob diferentes fontes de adubação e avaliados em duas épocas do ano.

QUADRADO MEDIO

\begin{tabular}{ccccc}
\hline FV & & & & \\
& $\mathrm{GL}$ & $\mathrm{MM}$ & $\mathrm{PB}$ & PRODMS \\
Trat. & 2 & $3.36^{*}$ & $0.13^{\text {** }}$ & $2217828.14^{*}$ \\
Genótipo & 1 & $1.860^{\text {ns }}$ & $0.00^{\text {ns }}$ & $25785.46^{\text {ns }}$ \\
Bloco & 2 & $0.63^{\text {ns }}$ & $0.05^{\text {ns }}$ & $188547.06^{\text {ns }}$ \\
TXG & 2 & $0.44^{\text {ns }}$ & $0,00^{\text {ns }}$ & $13459.28^{\text {ns * }}$ \\
CV (\%) & - & 9.36 & 3.59 & 42.62 \\
Média Geral & - & 8.64 & 3.81 & 1463.31 \\
\hline
\end{tabular}


$\mathrm{T}$ x G= interação tratamento e genótipo, CV $(\%)=$ Coeficiente de variação experimental, ns = Não significativo, $*$ = Significativo no nível de $5 \%$ de probabilidade pelo teste $\mathrm{F}$, $* *=$ Significativo no nível de $1 \%$ de probabilidade pelo teste F.

Analisando as médias apresentadas pelos clones quando cultivados nos diferentes tratamentos, verificou-se que o valor médio para cinzas ou matéria mineral, proteína bruta e massa seca foram de $8,64 \%, 3,81 \%$ e $1463,31 \mathrm{~kg} / \mathrm{Ha}$ respectivamente. (Tabela 1).

Nos testes de média realizados, podemos verificar que os teores de MM sobressaíram com a adubação orgânica com média de 9,50\% (Tabela 2). Araújo (2002) encontrou teor de MM igual a $10,21 \%$ para a palma gigante e $7,00 \%$ para a palma miúda. Tosto et al. (2007) obtiveram 16,30\%, valor maior ao apresentado neste trabalho. De acordo com Ferreira et al. (2006), independentemente do gênero, a palma forrageira apresenta teores consideráveis de matéria mineral, muito embora estes valores variem de acordo com a espécie, clones, idade dos cladódios, zona geográfica e época do ano. Batista et al. (2003) relatam que as variações na matéria mineral são provavelmente decorrentes das diferentes condições edafoclimáticas e de manejo as quais a palma forrageira é submetida.

Para os teores de PB, pode-se observar que foram maiores nas plantas que receberam adubação orgânica e também para a testemunha 3,89\% e 3,90\%, respectivamente, diferindo estatisticamente das plantas cultivadas com adubação química 3,61\% (Tabela 2). Os valores encontrados estão próximos dos teores descritos na literatura (Albuquerque \& Santos, 2005 e Santos et al. ,2006). A proteína bruta compreende um grande grupo de substâncias com estruturas semelhantes, porém com funções fisiológicas muito diferentes. Albuquerque \& Santos (2005) estudando três cultivares de palma forrageira (palma cv. gigante; palma cv. redonda; palma cv. miúda), observaram que estas apresentavam diferentes teores de proteína bruta (PB); 4,83, 4,21 e 2,55\%, respectivamente. Santos et al. (2006) encontrou em suas pesquisas em relação aos teores de proteína bruta do clone IPA-20 valor referente a 5,5\%.

Tabela 2. Valores médios para produtividade de cinzas ou matéria mineral $(\mathrm{MM})$, proteína bruta $(\mathrm{PB})$ e produtividade de matéria seca (PRODMS) (Kg/ha) avaliadas em dois genótipos de palma miúda (Nopalea cochenillifera Salm- Dyck) cultivados sob diferentes fontes de adubação.

\begin{tabular}{llll}
\hline \multicolumn{4}{c}{ TABELA DE MEDIAS } \\
& MM & PB & PRODMS \\
Tratamentos & & & \\
TESTEMUNHA & $8.106667 \mathrm{~B}$ & $3.908167 \mathrm{~A}$ & $1132.858167 \mathrm{~B}$ \\
ADUBAÇAO & $9.500000 \mathrm{~A}$ & $3.893667 \mathrm{~A}$ & $2164.957333 \mathrm{~A}$ \\
ORGANICA & & & \\
ADUBAÇÄO & $8.326667 \mathrm{~B}$ & $3.641000 \mathrm{~B}$ & $1092.138000 \mathrm{~B}$ \\
QUIMICA & & & \\
Genótipo & & & \\
IPA SERTÄNEA & $8.322222 \mathrm{~B}$ & $3.817667 \mathrm{~B}$ & $1501.166556 \mathrm{~B}$ \\
V26 & $8.966667 \mathrm{~B}$ & $3.810889 \mathrm{~B}$ & $1425.469111 \mathrm{~B}$ \\
\hline
\end{tabular}

Para produtividade de matéria seca (PRODMS), observou-se que o tratamento adubação orgânica apresentou maior PRODMS (2164,95 kg/ha) diferindo estatisticamente dos demais tratamentos. Observou-se que o tratamento que apresentou maior produtividade apresentou o maior valor de matéria mineral e de proteína Bruta. 
Segundo Santos et al. (2006) o emprego de adubação orgânica com uso de um espaçamento adequado, pode propiciar aumentos de mais de $100 \%$ na produção, a cada dois anos.

\section{CONCLUSÃO}

Conclui-se que a adubação orgânica apresentou os melhores resultados para os teores de cinzas ou matéria mineral $(\mathrm{MM})$, proteína bruta $(\mathrm{PB})$ e produtividade de massa seca (MS) para a região de Feira de Santana.

\section{REFERÊNCIAS}

ALBUQUERQUE, S. G.; SANTOS, D. C. Palma forrageira. In: KIILL, L. H. P.; MENEZES, E. A. Espécies vegetais exóticas com potencialidades para o semiárido brasileiro: Brasília, DF: Embrapa Informação Tecnológica, 2005. cap.3, p. 91- 127.

BATISTA, A.M.; MUSTAFA, A.F.; McALLISTER, T. Effects of variety on chemical composition, in situ nutrient disappearance and in vitro gas production of spineless cacti. Journal of the Science of Food and Agriculture, v.83, n.5, p.440-445, 2003. http://dx.doi.org/10.1002/jsfa.1393.

DUBEUX JÚNIOR, J. C. B.; ARAÚJO FILHO, J. T.; SANTOS, M. V. F.; LIRA, M. A.; SANTOS, D. C.; PESSOA, R. A. S. Adubação mineral no crescimento e composição mineral da palma forrageira - Clone IPA-20. Revista Brasileira de Ciências Agrárias, v. 5, n. 1, pp. 129- 135, 2010.

LOPES, et al. Composição bromatológica de palma forrageira (NopaleacoccinelliferaSalmDyck) amonizada. Revista Magistra, Cruz das Almas-BA, v. 17, n. 3, p. 107-113, set./dez., 2005.

MERTENS, D.R. Creating a system for meeting the fiber requirements of dairy cows. Journal of Dairy Science, v.80, n.7, p.1463-1481, 1997.

PEREIRA, E. S. Determinação das frações proteicas e de carboidratos e estimativa do valor energético de forrageiras e subprodutos da agroindústria produzidos no Nordeste Brasileiro. Semina: Ciências Agrárias, Londrina, v. 31, n. 4, p. 1079-1094, out./dez. 2010

SILVA NETO, F. L.; ANDRADE, R. L.; SOUTO, J. S.; BEZERRA, D. M.; SILVA, A. L. N.; FERREIRA, S. D.; SOUZA, B. V.; RODRIGUES, M. Q. Crescimento da palma forrageira (Opuntia fícus- indica Mill.) em função do espaçamento e doses de fósforo. Anais. ZOOTEC, João Pessoa, 2008. 4p.

TOSTO, M. S. L.; ARAÚJO, G. G. L.; OLIVEIRA, R. L; BAGALDO, A. R.; DANTAS, F. R.; MENEZES, D. R.; CHAGAS, E. C. O. Composição química e estimativa de energia da palma forrageira e do resíduo desidratado de vitivinícolas. Rev. Bras. Saúde Prod. An., v.8, n.3, p. 239-249, jul/set, 2007. 